\title{
Understanding the basis of treatment choices for varicose veins: a model of decision making with the repertory grid technique
}

\author{
Deborah Baker
}

\begin{abstract}
Objectives-To use the repertory grid technique as a method for identifying and rating the criteria that clinicians use to make a choice between the different treatment options for patients with a common condition such as varicose veins.

Design-The "expert panel" consensus method for rating the appropriateness of clinical procedures was modified with an existing psychometric method, the repertory grid technique. To identify the criteria used to decide about treatment, the panel members compared and contrasted a range of nine "treatment prototypes". They were then required to rate each criterion for its relevance to each treatment prototype.
\end{abstract}

Setting-The panel was selected from different geographical locations in the South Western Regional Health Authority.

Subjects-The expert panel was composed of six vascular surgeons, three from teaching and three from non-teaching hospitals; two general practitioners who were also clinical assistants in vascular surgery; and one honorary senior lecturer in general practice.

Main measures-Decision making criteria were categorised according to their content. Their frequency of replication was noted-that is, how many clinicians used the same criterion. Computer analysis of the rating scores for the nine panel members identified the relative importance of each treatment criterion for each treatment option.

Results-161 criteria for the treatment of varicose veins were elicited from the nine participants. These criteria were wide ranging, from clinical indications $(48 \%$ of those used), to social (32\%), and organisational factors (20\%). Clinical indications were more likely to be used when deciding about surgery as a high priority, whereas social and organisational criteria were more likely to be applied in decisions about surgery as a low priority, day case surgery, and cosmetic surgery.

Conclusions-The repertory grid technique proved to be effective in modelling decision making for a condition such as varicose veins: its use enabled both the identification of the wide range of criteria underlying the decision to treat and the exploration of the relative importance of these criteria in relation to several treatment options. Its potential as a method for reducing variation in clinical decision making and thus improving distribution of high quality care lies in its ability to pinpoint dilemmas of decision making rather than as the basis for drawing up guidelines to regulate decision making practice.

(Quality in Health Care 1996;5:128-133)

Keywords: clinical decision making, varicose veins, repertory grid technique

Introduction

Variation in the rate of patients receiving hospital treatment for common conditions such as varicose veins has been consistently linked to differences in decision making between individual clinicians rather than population need or the supply of hospital beds or health service personnel. ${ }^{1-3}$ Such variation can be expressed as either overuse or underuse of health care, but whatever its manifestation, it indicates an unevenness in the quality of care provided for patients. One attempt to reduce such variation and thus equalise the distribution of high quality care has been the development of consensus methods designed to establish a level of agreement about the criteria defining when it is and when it is not appropriate to recommend a particular procedure, with the end point of formulating guidelines for best practice. The full range of these methods has been well documented elsewhere, ${ }^{4}{ }^{5}$ but the focus of this paper is an alternative method based on modelling the decision making of clinicians for a common condition (varicose veins) in which the decision to be made involves choosing between several different treatment options rather than only twonamely, the performance or not of a particular procedure. This approach is based on an existing psychometric method, the repertory grid technique. Before describing this method, it is necessary to consider the limitations of "appropriateness rating" consensus methods when applied to this kind of decision making context.

\section{APPROPRIATENESS RATING}

The most typical example of the appropriateness rating methods is the "expert panel" method developed by the RAND organisation in the United States ${ }^{6}$ for the Health Services Utilisation Study (HSUS), which sought to find whether high rates of use were associated with high rates of inappropriate care. It was specifically designed to focus on procedures rather than conditions because a large proportion of the expenditure in the health field depends on decisions about performing or 
not performing a procedure. Reducing inappropriate care has thus considerable implications for reducing cost, as well as improving quality. It has since been applied to procedures as various as hysterectomy, ${ }^{7}$ cholecystectomy, ${ }^{8}$ and prostatectomy. ${ }^{9}$

The method initially involves the compilation of a literature review to incorporate all the information available in the medical literature on effectiveness, efficacy, costs, and complications for the procedure in question. At the same time a list of indications is drawn up based essentially on clinical criteria including symptoms, medical history, and results of previous diagnostic tests. The number of indications can vary between 50 and 3000 . An expert panel is then selected, most often nine in number and including both doers and nondoers of the procedure. These panellists are sent the literature review and the list of indications that they are required to rate along a nine point scale in terms of their appropriateness as an indication for the procedure involved. Appropriateness is in this instance defined as when "the expected health benefit exceeds the expected negative consequences by a sufficiently wide margin that the procedure is worth doing ... excluding consideration of monetary cost." A rating of 1 indicates extreme inappropriateness, 9 extreme appropriateness.

The panel is then convened for a face to face meeting and each panellist is presented with anonymised ratings for the group, with their own marked out. All areas of major disagreement are considered and the indications are then rerated. A mean score of the panel's agreement is then calculated for each indication. The final product of this procedure is a published report containing the literature review plus appropriateness ratings for each indication. ${ }^{7}$ However, this consensus method is based on several assumptions about clinical decision making that limit its appropriateness to other general decision making contexts. The first is that decisions about treatment can be circumscribed by a list of clinical indications. Evidence indicates, however, that the full range of criteria governing clinical decision making extends far beyond the purely clinical to include patient perceptions of their condition, their social circumstances, the organisation of care, and the availability of resources. ${ }^{111}$ In a recent study examining how physicians chose drugs, Denig et $\mathrm{al}^{12}$ found that a model including only biomedical criteria predicted preferred treatment in only $53 \%$ of cases, whereas one including aspects of the social environment and knowledge gained from past experience predicted preferred treatment in three out of four cases. Another assumption made by the expert panel method is that clinicians will weigh up the pros and cons of a long list of indications before making a decision. Studies of the decision making process have, however, shown that clinicians often base their decision making on simplified rules of thumb, which are stored in memory as prototypical cases ${ }^{13}{ }^{14}$ rather than as long lists of appropriate indications.
Finally the expert panel method is deliberately restricted to the choice of whether to treat or not to treat given certain indications, whereas decision making about the treatment of common conditions more often than not involves choosing between a range of treatment options, a task which inevitably requires some judgement to be made about the relative merits of one treatment when compared with another. For example, in the case of treatment for varicose veins, there is the choice between conservative treatment such as self help or support stockings, outpatient procedures such as injection sclerotherapy, surgery for complications, for symptoms, or for cosmetic reasons, or indeed whether to treat the patient as a day patient or admit for an overnight stay.

It would seem sensible therefore that any method seeking to modify existing decision making practice regarding such conditions should be capable of eliciting the full range of criteria that govern decisions about treatment and specifying how these are likely to be used by clinicians in deciding between different forms of treatment. Although none of the existing consensus methods model the decision making process in this way, the repertory grid technique, a method that has been used for many years in social scientific research, can fulfill these requirements. The study reported below shows how this technique can be used to modify the expert panel method to provide a more focused picture of the criteria clinicians use to choose between different treatment options and how they are ranked to decide about the most appropriate treatment for each patient. The approach is illustrated with reference to a study that was conducted in 1993 in the South Western Region as part of a project to draw up guidelines for the treatment of varicose veins. ${ }^{15}$

\section{Methods}

REPERTORY GRID TECHNIQUE

The repertory grid technique was originally developed by George Kelly as an aid to psychotherapy, ${ }^{16-18}$ to map the way in which a person constructs a particular aspect of his or her world. However, the technique has since been applied in many situations because it provides a flexible and adaptable way of systematically measuring how people think about the people and the events they encounter in their lives. Examples of its recent use in health services research are various and include uncovering patient perceptions of back pain, ${ }^{19}$ identifying the reasons for adolescent smoking, ${ }^{20}$ and evaluating health related quality of life. ${ }^{21}$

\section{Framework for the repertory grid}

A repertory grid is first and foremost defined by its "elements"; these are designed to focus the thoughts of the participants on the area of investigation in question. ${ }^{17}$ They can, for example, be people known to the subject or situations a person might find her or himself in, but in this case they consisted of nine treatment options to which patients could be recommended: these are shown in box 1 and 


\section{Varicose vein treatment prototypes for the repentory gutd \\ - Someone for whom you would recommend self help or support stockings \\ - Someone for whom you would recommend surgery as a hightpriority \\ - Someone for whom you would recommend surgery as a low priority \\ - Someone who you would admit as an emergency \\ - Someone for whom you would recommend cosmetic surgery \\ - Someone for whom you would recommend bedrest \\ - Someone for whom you would recommend surgery as a day case \\ - Someone for whom you would recommend injection sclerotherapy \\ - Someone for whom surgery was contraindicated}

Box 1

from here on will be referred to as "treatment prototypes".

They were drawn up in conjunction with a vascular surgeon, a consultant in public health medicine, a senior lecturer in general practice, and a research fellow who had studied variation in the treatment of varicose veins in the South Western Region.

SELECTION OF THE EXPERT PANEL

Expert panels are usually made up of nine to 12 expert physicians who perform a particular procedure and who are representative of different geographical locations. In this case the panel also included general practitioners, because the treatment of varicose veins spans both primary and secondary healthcare settings. Ten vascular surgeons in the South West Region were invited by letter to participate in the study. Six agreed, three from teaching and three from non-teaching hospitals, all in different locations. Also three general practitioners agreed to join the panel. Two of these were clinical assistants in vascular surgery, selected from a list provided by the vascular surgeons. One was an honorary senior lecturer in general practice.

\section{Identification of treatment criteria}

The procedure began by each participant completing the first stage of the repertory grid in face to face interviews; I conducted these interviews, which lasted 15-20 minutes and were tape recorded.

To identify criteria used to decide about treatment the participants were presented with the treatment prototypes in combinations of three and asked to identify which two they would see as being similar to one another and distinct from the third, and why.

For example, in stage 1, illustrated in box 2, three treatment prototypes given were someone for whom you would recommend surgery on a high priority basis, someone who you would admit as an emergency, and someone for whom you would recommend cosmetic surgery. The first two were seen as being similar to one another and distinct from the third. The reasons given were that the first two patients were likely to have gross varicose ulceration, were likely to be relatively elderly, and were likely to have bleeding from veins or ulcers; in contrast, someone for whom you would recommend cosmetic surgery would have no varicose ulceration, no evidence of bleeding from the veins or ulcers, and was more likely to be younger. These descriptions of similarity and difference constitute the bipolar constructs of the grid. These will now be referred to as the "treatment criteria". Different combinations of three treatment prototypes were presented to each participant until the point was reached when no new treatment criteria were being generated. The combinations were the same for each participant, as was the order in which they were presented. In general eight to 10 combinations of treatment prototypes were needed to elicit the full range of treatment criteria from each participant. The average number of criteria produced by each clinician was 18 , with a range between 14 and 22 .

\section{Rating procedure}

After each of these interviews a booklet was sent to the participants in which they were required to rate along a seven point scale each of the treatment criteria elicited in the first stage of the repertory grid in terms of its applicability in relation to each of the nine treatment prototypes. Stage 2, illustrated in box 2 , shows this task for one treatment prototype and three possible treatment criteria. The product of this exercise was a grid of figures with a rating from 1 to 7 for each treatment criterion in relation to each treatment prototype.

The use of the repertory grid technique thus allowed participants to compare and contrast a range of possible treatment options rather than simply to look at whether to treat or not to treat. Also the criteria underlying the choice between different forms of treatment were compiled as a consequence of identifying the range of criteria that participants would use in each case, rather than assuming that clinical criteria were the most important.

\section{Comparison of treatment prototypes with the repertory grid technique \\ Stage 1 \\ Which two treatment prototypes are similar? \\ How are they similar and distinct from the third? \\ Similar \\ Someone for whom you would recommend surgery as a high priority \\ Someone who you would admit as an emergency \\ Gross ulceration \\ Patient is over 55 \\ Evidence of bleeding from ulcers or veins}

Stage 2

Each treatment prototype is rated in relation to the elicited treatment criteria
For example, someone for whom you would recommend surgery as a high priority

Gross ulceration

Patient is over 55

Evidence of bleeding

from veins or ulcers
Distinct

Someone for whom you would recommended cosmetic surgery

No varicose ulceration

Patient is under 55

No evidence of bleeding from ulcers or veins

No varicose ulceration

Patient is under 55

No evidence of bleeding

from veins or ulcers 


\section{Analysis of repertory grids}

The analysis of the repertory grid data established the range of criteria used by the participants to distinguish between the treatment prototypes, the degree of agreement as to the usefulness of each criterion when deciding about treatment, and the relative importance of each criterion in decision making about each treatment prototype. To achieve these aims, these procedures were followed:

(1) All the treatment criteria elicited from the participants were pooled and categorised according to their content. For each criterion

Table 1 Range and content of treatment criteria elicited from nine expert panel members

\begin{tabular}{|c|c|c|}
\hline Category & Contents of treatment criteria & $n(\%)$ \\
\hline & Signs and symptoms: & \\
\hline 1 & Heavy aching legs or unsightly legs, no aching & 9 \\
\hline 2 & Symptomatic or asymptomatic varicose veins & 6 \\
\hline 3 & $\begin{array}{l}\text { Saphenofemoral incompetence detected by Doppler or no } \\
\text { saphenofemoral incompetence }\end{array}$ & 6 \\
\hline 4 & $\begin{array}{l}\text { Saphenopopliteal incompetence detected by Doppler or no } \\
\text { saphenopopliteal incompetence }\end{array}$ & 3 \\
\hline \multirow[t]{2}{*}{5} & Specific perforator incompetence can or cannot be isolated & $\begin{array}{l}1 \\
25(16)\end{array}$ \\
\hline & Complications: & \\
\hline 6 & Varicose ulceration or no varicose ulceration & 9 \\
\hline 7 & Bleeding from veins or ulcers or no bleeding from veins or ulcers & 7 \\
\hline \multirow[t]{3}{*}{8} & $\begin{array}{l}\text { Skin change or varicose eczema or no skin change or varicose } \\
\text { eczema }\end{array}$ & 5 \\
\hline & & $21(13)$ \\
\hline & Type and location: & \\
\hline 9 & Primary or first presentation varicose veins or recurrent varicose veins & 6 \\
\hline 10 & Varicose veins above knee or no varicose veins above knee & 4 \\
\hline 11 & Varicose veins below knee or no varicose veins below knee & 4 \\
\hline 12 & Single leg or bilateral varicose veins & 2 \\
\hline 13 & Localised or extensive varicose veins & 2 \\
\hline \multirow[t]{2}{*}{14} & Tourniquet reveals uncontrolled or controlled varicose veins & $\begin{array}{l}1 \\
19(12)\end{array}$ \\
\hline & History or comorbidity: & \\
\hline 15 & $\begin{array}{l}\text { History or evidence of deep vein thrombosis or no history or evidence } \\
\text { of deep vein thrombosis }\end{array}$ & 5 \\
\hline 16 & Comorbidity - for example, angina - need or need not be considered & 1 \\
\hline 17 & $\begin{array}{l}\text { Comorbidity - for example, hypertension, arthritic hip - need or need } \\
\text { not be considered }\end{array}$ & 1 \\
\hline 18 & Evidence or no evidence of peripheral arterial disease & 1 \\
\hline 19 & Serious illness or no serious illness accompanying varicose veins & 1 \\
\hline 20 & Patient has or has not a history of valvar incompetence & 1 \\
\hline \multirow[t]{2}{*}{21} & Patient is or is not a suitable anaesthetic risk & $\begin{array}{l}1 \\
11(7)\end{array}$ \\
\hline & Patient's characteristics: & \\
\hline 22 & Patient is more or less likely to be older $(>55)$ & 9 \\
\hline 23 & Patient is or is not fit & 7 \\
\hline 24 & Patient is or is not overweight & 6 \\
\hline 25 & Patient is more likely to be female or male & 4 \\
\hline 26 & Patient is relatively affluent or poor & 2 \\
\hline \multirow[t]{3}{*}{27} & $\begin{array}{l}\text { Patient's social circumstances important or not important in deciding } \\
\text { about treatment }\end{array}$ & 1 \\
\hline & & $29(18)$ \\
\hline & Patient's perceptions, preferences, and lifestyle: & \\
\hline 28 & Patient preferences about treatment a high or low priority & 6 \\
\hline 29 & Patient has good support or no support at home & 6 \\
\hline 30 & Patient is anxious or not anxious about appearance of legs & 5 \\
\hline 31 & Patient likely or unlikely to comply with treatment at home & 3 \\
\hline 32 & Patient lives close to or distant from hospital & 1 \\
\hline 33 & Patient is or is not easily ambulant & 1 \\
\hline \multirow[t]{2}{*}{34} & Patient's symptoms do or do not interfere with daily living & $\begin{array}{l}1 \\
23(14)\end{array}$ \\
\hline & Organisation of care: & \\
\hline \multirow[t]{2}{*}{35} & $\begin{array}{l}\text { Factors affecting the timing of surgery - for example, surgery is likely } \\
\text { or not likely to require saphenofemoral disconnection with ligation } \\
\text { bilaterally; surgery is or is not likely to require saphenofemoral } \\
\text { disconnection with ligation unilaterally; surgery will take a relatively long } \\
\text { or short time; surgery likely to take }>1 \mathrm{~h} \text { or }<1 \mathrm{~h} \text {; surgery likely to take } \\
<30 \mathrm{~min} \text { or }>30 \mathrm{~min} \text {; treatment likely or not likely to require high ties }\end{array}$ & 8 \\
\hline & Patient treated in $<3$ months (high priority) or $>3$ months (low priority) & 6 \\
\hline & Appropriate or inappropriate referral from GP & 5 \\
\hline 37 & Level of resources important or unimportant constituent of decision & 5 \\
\hline 38 & Treatment most often carried out by consultant or senior house officer & 3 \\
\hline 39 & Veins previously successfully or unsuccessfully treated & 3 \\
\hline 40 & Varicose ulcers likely or unlikely to respond to conservative treatment & 2 \\
\hline \multirow[t]{2}{*}{$\begin{array}{l}40 \\
41\end{array}$} & Political criteria important or not important in deciding about this & 1 \\
\hline & & $\begin{array}{l}33(20) \\
161(100)\end{array}$ \\
\hline
\end{tabular}

the number of replications was noted-that is, the number of participants who used the criterion as a means of differentiating between the prototypes.

(2) A principle components analysis on the Ingrid computer program was used to examine the correlation between treatment criteria and treatment prototypes for each individual participant's grid. ${ }^{22}$ The main purpose of this type of analysis is to reduce the number of dimensions of multivariate data by transforming a set of observed and correlated variables into a new set of variables that are uncorrelated and ordered according to their decreasing importance; these new variables are called the principle components. If the first two components account for a large proportion of the total variation then the values of the first two component scores can be plotted in each case and the dimensions reduced to two; clusters of variables described by the first two components can then be identified. ${ }^{23} \mathrm{~A}$ measure of the relations between each treatment criterion and each treatment prototype on the first two components of the grid is expressed by angular distance (degrees) and cosines (correlations). This analysis initially produced for each participant a model of the relation between treatment criteria and the treatment prototypes. With these analyses, comparison was then made between participants by calculating the mean angular distance (and its equivalent correlation) between each of those treatment criteria used by five or more of the participants (that is, those that over $50 \%$ of participants used) and each treatment option (based on the assumption that those criteria that correlated most highly with each treatment option were those that were most relevant for deciding about treatment).

\section{Results}

Table 1 shows the results of the first stage of the analysis. A total of 161 criteria were elicited from the nine participants by the repertory grid technique. When they were categorised according to their content and the number of replications counted, 41 distinct criteria emerged as the basis for decision making about the treatment of varicose veins.

The criteria underlying choice of treatment were by no means restricted to clinical indications: $76(48 \%)$ consisted of clinical signs and symptoms, complications, details of the location, and extent of varicosity as well as consideration of previous history and comorbidity. The remaining $85(52 \%)$, however, reflected patient and organisational factors. These included patients' characteristics such as age and sex, patients' perceptions of their condition-for example, anxiety about the unsightliness of their legs, their preferences about treatment, lifestyle factors such as their home circumstances, and whether their condition affected their ability to work $(52(32 \%))$. Those involved in the organisation of treatment included the time it would take, its relative priority in relation to other components of workload, and the availability of 
Table 2 Correlation* between the most frequently used treatment criteriat and four treatment prototypes

\begin{tabular}{|c|c|c|c|c|}
\hline \multirow[t]{2}{*}{ Treatment criteria } & \multicolumn{4}{|c|}{ Treatment prototypes } \\
\hline & $\begin{array}{c}\text { High } \\
\text { priority } \\
\text { surgery }\end{array}$ & $\begin{array}{l}\text { Low } \\
\text { priority } \\
\text { surgery }\end{array}$ & $\begin{array}{l}\text { Cosmetic } \\
\text { surgery }\end{array}$ & $\begin{array}{l}\text { Day case } \\
\text { surgery }\end{array}$ \\
\hline \multicolumn{5}{|l|}{ Signs, symptoms, and complications: } \\
\hline Varicose ulceration & 0.67 & - & - & - \\
\hline No varicose ulceration & - & 0.59 & - & 0.52 \\
\hline Saphenofemoral incompetence & 0.72 & - & - & - \\
\hline $\begin{array}{l}\text { No evidence of saphenofemoral } \\
\text { incompetence }\end{array}$ & - & - & - & - \\
\hline Bleeding from veins or ulcers & 0.62 & - & - & - \\
\hline No bleeding from veins or ulcers & - & 0.61 & - & - \\
\hline Skin change or varicose eczema & 0.75 & - & - & - \\
\hline $\begin{array}{l}\text { No evidence of skin change or varicose } \\
\text { eczema }\end{array}$ & - & - & - & - \\
\hline First presentation varicose veins & - & - & - & - \\
\hline Recurrent varicose veins & - & - & - & - \\
\hline Evidence of deep vein thrombosis & - & - & - & - \\
\hline No evidence of deep vein thrombosis & - & - & - & 0.62 \\
\hline Unsightly aching legs & - & 0.56 & - & - \\
\hline Unsightly legs no aching & - & - & 0.73 & - \\
\hline Symptomatic varicose veins & - & 0.58 & - & - \\
\hline Asymptomatic varicose veins & - & - & 0.70 & - \\
\hline \multicolumn{5}{|l|}{ Patient's characteristics: } \\
\hline Patient anxious about appearance of legs & - & 0.65 & 0.63 & - \\
\hline $\begin{array}{l}\text { Patient is not concerned about appearance } \\
\text { of legs }\end{array}$ & - & - & - & - \\
\hline $\begin{array}{l}\text { Patient preference about treatment is } \\
\text { important }\end{array}$ & - & - & 0.69 & - \\
\hline $\begin{array}{l}\text { Patient preference about treatment is not } \\
\text { important }\end{array}$ & 0.63 & - & - & - \\
\hline Patient is younger $(<55)$ & - & - & 0.66 & 0.72 \\
\hline Patient is older $(>55)$ & - & - & - & - \\
\hline Patient is fit & - & - & - & 0.67 \\
\hline Patient is unfit & - & - & - & - \\
\hline Patient is overweight & - & - & - & - \\
\hline Patient is not overweight & - & - & - & 0.59 \\
\hline Patient has good support at home & - & - & - & 0.8 \\
\hline Patient has not support at home & - & - & - & - \\
\hline \multicolumn{5}{|l|}{ Organisation of care: } \\
\hline $\begin{array}{l}\text { Patient waits under three months for } \\
\text { treatment }\end{array}$ & 0.81 & - & - & - \\
\hline $\begin{array}{l}\text { Patient waits over three months for } \\
\text { treatment }\end{array}$ & - & 0.67 & - & - \\
\hline Surgery will take a relatively short time & - & - & - & 0.75 \\
\hline Surgery will take a relatively long time & - & - & - & - \\
\hline $\begin{array}{l}\text { Important to consider availability of } \\
\text { resources }\end{array}$ & - & - & - & 0.69 \\
\hline Appropriate referral from GP & - & - & - & - \\
\hline Inappropriate referral from GP & - & - & - & - \\
\hline
\end{tabular}

* The correlations in this table represent the relations between a treatment prototype and the positive or negative pole of the treatment criterion. The correlations included in the table are positive or negative pole
those for which $r>0.5$.

† Those criteria used by five or more participants in the repertory grid exercise.

resources for the treatment of varicose veins $(33(20 \%))$

Table 2 shows the results of the second stage of the analysis, when the relations between the most often used criteria (those mentioned by five or more participants) and each treatment option were examined. The four surgical treatment options have been selected as illustrations. Table 2 shows that the relative importance of each treatment criterion differed considerably between the treatment prototypes.

For high priority surgery clinical indications defining varicose veins with complications were most important - for example, ulceration and skin change and bleeding from veins or ulcers. High priority was also defined by waiting times for patients; the most commonly mentioned time being under three months. Another important factor was that the decision to treat was driven by the clinician: patients' preferences about treatment were considered of low importance in relation to this treatment option. For low priority surgery the most important criteria were those describing the absence rather than the presence of complications and evidence of symptomatic varicose veins. Also of relevance was the patients' anxiety about the appearance of their legs; waiting time for surgery was defined as at least three months. Criteria for cosmetic surgery suggested that treatment was driven by the patient, depending on patients' perceptions such as their relative anxiety about the appearance of their legs and their preferences about treatment. Such factors were related to a clinical diagnosis of asymptomatic varicose veins. For day case surgery a different set of criteria came into play. Most important considerations were patients' characteristics such as their home circumstances-for instance, whether there was anyone to care for them at home, and their fitness, age, and weight. Other factors were those concerned with the organisation of treatment such as whether resources were available, the location of veins, and the complexity of treatment they required, which had direct bearing on the amount of time that surgery would take.

\section{Discussion}

The use of the repertory grid technique to model decision making about the treatment of varicose veins confirmed the view that clinical decision making for such conditions involves the use of a wide range of criteria from clinical indications to patients' perceptions and preferences and to organisational factors. It also showed that only a few criteria were of importance in deciding about a particular treatment option suggesting that, in this case, decision making was dependent on applying a limited range of selected criteria. Moreover the results indicated that variation in decision making could arise from the actual content of criteria being used rather than agreement or disagreement about their appropriateness as indications for treatment. For example, the criteria used to decide about surgery as a high priority were relatively clear cut. They were organised around the discernible clinical indications defining complicated varicose veins. Surgery for complicated varicose veins, however, accounts for a very small proportion (about $4 \%$ ) of the total number of referrals attending the outpatient clinic. In contrast, decisions about the other treatment options were dependent on much less easily discernible criteria - whether legs ached, the depth of trauma that unsightly legs may cause, the availability of resources, etc. A different kind of judgement was required here: one that involved balancing several factors each of which is surrounded by a considerable degree of ambiguity. So, although there was agreement that these were the most important criteria for deciding about treatment, the very nature of such criteria is likely to lead to a considerable amount of variation in interpretation and therefore in practice.

In the light of these findings, the expert panel method developed by the RAND corporation is limited in the extent to which it can delineate appropriate care for conditions such as varicose veins. It would seem to be most 
useful when the choice is whether or not to perform a particular procedure for which the decision rests on clinical indications that are relatively dear cut. The repertory grid technique, however, is more useful when examining decision making in which clinicians are likely to use a wide range of criteria to choose between several different treatment options. As an instrument for improving the quality of care, its usefulness lies not so much in producing a list of guidelines that serve to regulate practice, but as a means of pinpointing sources of ambiguity in decision making. Such information has two purposes. Firstly, as the basis for discussion between clinicians and other concerned groups about the type of change required to reduce the impact of such ambiguity on the delivery of care. Secondly, by modelling clinical decision making the repertory grid technique provides a means of identifying points in the decision making task where more precise measurement could inform clinicians about to make decisions. For example, for varicose veins, quality of life measurement, particularly the patients' perception of their condition and its impact on their lifestyle, could be a useful adjunct to the decision making process.

If this method were to be used for the purposes already outlined further consideration would need to be given to reliability and validity. In common with the expert panel method, in the repertory grid exercise criteria were rated by a panel of nine experts. Analysis of repertory grid data allows for both the examination of each participant's decision making as well as characteristic patterns between participants. However, judgements about the relative importance of criteria in deciding about treatment established by this process could be different if another group of clinicians were chosen. ${ }^{24}{ }^{25}$ These judgements thus require validation; this could be achieved by creating a standardised grid with the criteria elicited from the nine participants. Ratings from more and a wider range of clinicians, including consultants, general practitioners, registrars, and junior doctors, could then be collected. This procedure would have the added benefit of identifying any differences in decision making between different groups of practitioners. The use of prototypical cases to elicit decision making criteria is also controversial because decisions made about such prototypes could be qualitatively different from those made in practice. ${ }^{26}$ The evidence supporting this argument is inconclusive. If decision making does depend on the organisation of criteria around prototypical cases, then it would seem reasonable to use such cases as a means of eliciting decision making criteria. However, a check on reliability could be made by replicating the repertory grid procedure so that the treatment prototypes were matched to existing patients. Each participant would then complete two grids, one for treatment prototypes and one for an existing patient who had been referred for treatment, and the results would be compared.

An important strength of the repertory grid method to model decision making is that it allows quantitative measurement of qualitative decision making data, measurement that enables the summation of results for several participants. As such it provides a means of disentangling the complex set of factors underlying the treatment of common conditions such as varicose veins. Further development of this method as a tool for locating decision making dilemmas characterising the treatment of common conditions would provide a rational basis for considering issues surrounding variation in clinical practice and the equitable distribution of high quality care.

This work was carried out at the Department of Social Medicine, University of Bristol under the directorship of Professor Stephen Frankel and was funded by the Department of Health. I thank Dr Margaret Robbins, Dr Ian Harvey, and of Health. I thank Dr Margaret Robbins, Dr Ian Harvey, and Ben Toth at the Department of Social Medicine and Mr Derek Alderson and Professor Jonn Farndon at Bristol Royal Infirmary (UBHT) for their helpful assistance and advice. I am also grateful for the considered comments of three anonymous
reviewers. The views expressed are entirely my own.

1 Sanders D, Coulter A, McPherson K. Variations in hospital admission rates: a review of the literature. London: Kings Fund, 1989.

2 Roos NP, Roos LL. Surgical rate variations: do they reflect the health or socio economic characteristics of the populathe health or socio economic character

3 Wennberg J. Practice variations and the need for outcomes research. In: Ham C, ed. Health care variations. London: Kings Fund, 1985

4 Fink A, Kosecoff J, Chassin M, Brook RH. Consensus methods: characteristics and guidelines for use. $A m \mathcal{F}$ Public Health 1984;74:979-83.

5 Jones J, Hunter D. Qualitative research: consensus methods for medical and health services. $B M 7$ 1995;311:376-80.

6 Brook RH, Chassin MR, Fink A. A method for the detailed assessment of the appropriateness of medical technologies. Int $\Im$ Technol Assess Health Care 1986;2:53-63.

7 Bernstein SJ, McGlynn EA, Kamberg CJ, Chassin MR, Goldberg GA, Slu AL, et al. Hysterectomy: a literature review and ratings of appropriateness. Santa Monica, CA: RAND Corporation, 1992. (JR-04.)

8 Scott AK, Black N. Appropriateness of cholecystectomy in the United Kingdom - a consensus panel approach. Gut 1991;32:1066-70.

9 Hunter DJW, McKee CM, Sanderson CFB, Black NA. Appropriateness of prostatectomy: a consensus panel approach. $\mathcal{F}$ Epidemiol Community Health 1994;48:58-64.

10 Clark JA, Potter DA, McKinlay JB. Bringing social structure back into clinical decision making. Soc Sci Med 1991; 32:853-66.

11 Robbins M, Baker D, Harvey I, Toth B, Williams M. Variation in practice in the treatment of varicose veins. Bristol: University of Bristol, Health Care Evaluation Unit, 1992.

12 Denig P, Haaijer-Ruskamp FM, Wesseling H, Versluis A. Towards understanding treatment preferences of hospital physicians. Soc Sci Med 1993;36:915-24.

13 Elstein AS, Bordage G. Psychology of clinical reasoning. In: $\mathrm{J}$ Dowie, A Elstein, eds. Professional judgement. A reader in clinical decision making. Cambridge, Cambridge University Press, 1988.

14 Bordage $G$, Zacks $R$. The structure of medical knowledge in the memories of medical students and general practition-

15 Baker D, Toth B, Harvey I, Robbins M, Williams M. Guidelines for electing surgery: interim report. Bristol: University of Bristol Health Care Evaluation Unit, 1992.

16 Kelly GA. The psychology of personal constructs. New York: WW Norton, 1955.

17 Fransella F, Bannister D. A manual for repertory grid technique. London: Academic Press, 1977.

18 Ryle A. Frames and cages: the repertory grid approach to human understanding. Brighton: Sussex University Press, 1975.

19 O'Farrell U, Tate N. Aitken C. Attitudes and prognosis in acute back pain. $\mathcal{F}$ Psychosom Res 1993;37:415-22.

20 Lynch P. Adolescent smoking - an alternative perspective using personal construct theory. Health Educ Res 1995; 10:95-106.

21 Kendrick A, Joyce CRB, Trimble MR, Selai CE. A new method for evaluating health - related quality of life using method for evaluating health - related quality of 1994;3:48.

22 Slater P. Notes on INGRID. London: Institute of Psychiatry, 1972. (Unpublished manuscript.)

23 Chatfield C, Collins AJ. Introduction to multivariate analysis. London: Chapman and Hall, 1980

24 Brook RH, Park RE, Winslow CM, et al. Diagnosis and treatment of coronary disease: comparison of doctors' attitude in the USA and UK. Lancet 1988;i:750-3.

25 Hicks NR. Some observations on attempts to measure appropriateness of care. $B M \mathcal{F} 1994 ; 309: 730-3$.

26 Jones TV, Gerrity MS, Earp J. Written case simulations: do they predict physicians behaviour? $\mathcal{f}$ Clin Epidemiol 1990;43:833-40. 